\title{
O NOVO PRESIDENTE E O DIREITO FINANCEIRO: O QUE PODEMOS ESPERAR?
}

Coluna publicada em 16.10.2018:<https://www.conjur.com.br/2018-out-16/ contas-vista-onovo-presidente-direito-financeiro-podemos-esperar $>$

Estamos a poucos dias da eleição do próximo presidente da República e de todos os governadores (sem contar o Congresso Nacional e as Assembleias Legislativas, já definidos).

É o momento de analisar o que pretendem fazer em relação aos aperfeiçoamentos que o Direito Financeiro precisa. Afinal, há muito o que fazer nesse campo, e não se pode deixar passar mais quatro anos (ou oito, se considerada a hipótese de reeleição...) sem avançar nesse campo. É sempre bom lembrar que a lei orçamentária é a mais importante depois da Constituição, ${ }^{1}$ e o sistema de planejamento e orçamento precisa receber a merecida atenção dos governantes.

Havendo maior relevância da legislação financeira no âmbito federal, cabe-nos dar mais atenção às propostas dos dois candidatos que disputam a Presidência da República, expostas nos planos de governo que apresentaram, o que permite vislumbrar, ao menos em parte, o que se pode esperar.

Infelizmente as notícias não são as melhores, pois não se vê nos referidos documentos destaque significativo para as questôes relacionadas especificamente às reformas esperadas para o Direito Financeiro e a modernização do sistema orçamentário vigente. Um tanto genéricos, os planos apresentados não se aprofundam nas diversas propostas nem descem a detalhamentos que permitam fazer uma análise mais acurada sobre o que realmente pretendem os candidatos nesse campo.

Min. Carlos Ayres Britto, ADI-MC 4048-1/DF, j. 14.5.2008. 
O candidato que desponta como favorito até o momento, Jair Bolsonaro, em seu plano de governo, ${ }^{2}$ é o único que faz uma referência mais direta à alteração no sistema de planejamento e orçamento, com a adoção do "orçamento base-zero".

Propõe que se inverta a lógica dos gastos, obrigando cada gestor a justificar a demanda por recursos públicos, de modo que "o montante gasto no passado não justificará recursos demandados no presente ou no futuro", e enfatiza a necessidade de se ter prioridades, metas e acompanhamento dos recursos gastos durante a gestão (p. 18).

O tema do orçamento base-zero (OBZ) já foi objeto de abordagem específica neste espaço, Crise econômica pode criar o "orçamento recurso-zero", nesta edição, p. 241-244, quando foi sugerida, como medida a ser adotada, na proposta apresentada pelo PMDB no final do ano de 2015, denominada "Ponte para o Futuro", recolocando na agenda um tema que havia sido esquecido no debate orçamentário. Como ressaltado à época, trata-se de medida bastante positiva, reduz uma série de distorçôes ocorridas, especialmente na fase de elaboração da lei orçamentária, com boas perspectivas de promover melhor aproveitamento dos recursos públicos e evitar desperdícios de recursos. Nunca foi, no entanto, técnica fácil de ser implementada, o que tem sido um obstáculo à sua utilização como instrumento de aperfeiçoamento do sistema orçamentário. Uma boa oportunidade para que seja promovida uma tentativa de concretização, uma vez que presidentes recém-eleitos, e com maioria de votos, têm respaldo popular suficiente para impor as mudanças que são necessárias.

No mais, vemos no plano de governo do candidato propostas que apresentam reflexos importantes para o Direito Financeiro, por referirem-se a temas que têm relação próxima com os gastos públicos e a atividade financeira do Estado. Não é possível, no entanto, se aprofundar em cada uma delas, dadas as limitaçóes a que se propõe esse texto, em que se dará destaque às propostas de aperfeiçoamento do ordenamento jurídico em matéria financeira.

Nesse aspecto, destacam-se a ênfase na redução de gastos públicos (redução do número de ministérios - p. 17), desburocratização na descentralização dos recursos, facilitando as transferências intergovernamentais (Mais Brasil, menos Brasília - p. 19), redução da dívida pública pela promoção de superávit primário (p. 55), reforma da Previdência, introduzindo-se o sistema de capitalização (p. 57), e

2 O caminho da prosperidade. Proposta de plano de Governo. Constitucional. Eficiente. Fraterno. Brasil acima de tudo. Deus acima de todos. Bolsonaro 2018. Disponível em: <http://divulgacandcontas.tse.jus.br/candidaturas/oficial/2018/BR/BR/2022802018/280000614517// proposta_1534284632231.pdf>. 
reforma tributária, com a unificação de tributos federais, descentralização e municipalização dos recursos (p. 58). Evidentemente que praticamente todas as demais propostas envolvem gastos públicos, como educação, saúde, infraestrutura e tantos outros, mas cada um desses temas exige espaços próprios e muito mais amplos para que se possa debatê-los. Não faltará oportunidade nos anos que estão por vir.

O candidato Fernando Haddad não apresenta em seu programa ${ }^{3}$ proposta específica para o aperfeiçoamento da legislação que organiza o sistema financeiro e orçamentário, cabendo destaque a algumas questōes que têm reflexos no âmbito do Direito Financeiro.

A mais relevante é a proposta de reforma dos tribunais de contas, reconhecendo que "o papel de combater o mau uso do dinheiro público é fundamental, [mas os órgãos de controle] passaram a extrapolar suas funções, impondo aos órgãos do Executivo suas preferências de políticas públicas e formas de implementá-las", o que deve ser aperfeiçoado "com a alteração nos critérios de nomeação, instituição de tempo de mandatos, criação de Conselho Nacional e outros mecanismos de participação e controle social", para que a gestão pública "não seja regida exclusivamente por uma cultura de controles burocráticos que interdite a ação estatal" (p. 14).

A discussão sobre os critérios de nomeação e composição dos tribunais de contas é antiga. São muitos os casos em toda a federação de indicações que, em face da histórica predominância do caráter político, geram muitas vezes escolhas que levam às cortes de contas nomes que não honram o cargo com os requisitos exigidos pela Constituição. Colocam "joio no meio do trigo" e maculam a sua imagem, prejudicando o relevante trabalho que realizam, e ofuscam todos os demais que têm colaborado decisivamente para o aperfeiçoamento da gestão pública, no que os tribunais de contas têm sido instituiçôes extremamente relevantes. Esse tema já foi abordado em Moralização da administração pública: chegou a vez dos tribunais de contas, nesta edição, p. 359-366 e vale a releitura.

Nossos tribunais de contas têm sido os verdadeiros "guardiões do dinheiro público", como já mencionado neste espaço por mais de uma vez, ${ }^{4}$ e têm dado grande

3 Plano de Governo 2019-2022. Coligação o povo feliz de novo (PT - PCdoB - PROS). Disponível em: <http://divulgacandcontas.tse.jus.br/candidaturas/oficial/2018/BR/BR/2022802018/ 280000629808//proposta_1536702143353.pdf>.

4 Tribunais de Contas são os guardiōes do dinheiro público, nesta edição, p. 317-322; "PEC do padrão minimo" vai aperfeiçoar tribunais de contas, nesta ediçãa, p. 339-344. 
colaboração no aperfeiçoamento das políticas públicas. Vê-se que no mais das vezes as políticas públicas são corrigidas e aperfeiçoadas em face de ações propositivas dos tribunais de contas, razão pela qual há que se ter atenção no detalhamento da proposta, para que eventual mitigação "do controle burocrático que interdite a ação estatal" não esconda medidas voltadas a reduzir o poder fiscalizatório e punitivo dos tribunais de contas, que tanto têm colaborado no combate à corrupção.

O plano preconiza ainda a "revogação da Emenda Constitucional 95, que limita por vinte anos os investimentos e as políticas públicas capazes de gerar desenvolvimento", emenda essa que foi aprovada no final de 2016, para instituir o "Novo Regime Fiscal", mais conhecida como "Emenda do Teto de Gastos", com medidas voltadas a estabelecer limites máximos de caráter geral para os gastos públicos.

Propõe também o aperfeiçoamento do federalismo cooperativo, com o fortalecimento dos consórcios públicos e a assistência e capacitação dos gestores de estados e municípios, além de simplificar o sistema de repasses (p. 24); e uma reforma tributária com tributação de lucros e dividendos e a criação e implementação gradual de Imposto sobre o Valor Agregado (IVA) e reestruturação da tabela do Imposto de Renda (p. 42).

$\mathrm{Na}$ falta de maior aprofundamento das questôes mais diretamente relacionadas ao aprimoramento do Direito Financeiro que se podem encontrar nas propostas de ambos os candidatos, é oportuno oferecer sugestôes a eles, e com isso dar uma contribuição para o mandato que vão exercer.

$\mathrm{O}$ artigo $165, \$ 9^{\circ}$ da Constituição, cujo $30^{\circ}$ aniversário ocorreu há poucos dias, determinou que fosse elaborada lei complementar para dispor sobre as leis orçamentárias e normas de gestão financeira, papel que vem sendo cumprido até hoje pela Lei 4.320, de 1964. Uma lei que, evidentemente, já está defasada, sendo urgente sua substituição. E não faltam projetos prontos para serem aprovados. Alcunhados de "Lei de Qualidade Fiscal” e "Lei de Responsabilidade Orçamentária”, já tramitaram pelas comissões e por ambas as Casas do Congresso Nacional, e não mais se justifica que continuem dormindo nos escaninhos do Poder Legislativo. Já tratamos do assunto em 2013 em Responsabilidade orçamentária precisa de melhorias, ${ }^{5}$ além de outras, o que mostra quão antiga é a demanda pela sua aprovação. Registre-se ter sido inserido entre as prioridades do governo Temer, ao apresentar a "pauta alternativa" para a área econômica, após a suspensão das tratativas para a aprovação da reforma da Previdência (item 4 - Nova Lei de Finanças Públicas - PL 295), mas pouco falta

Nesta edição, p. 259-262. 
para o fim do governo, e não há notícias de que efetivamente tenha havido qualquer avanço nesse sentido. ${ }^{6}$

A Lei de Responsabilidade Fiscal, bem mais recente, não é mais tão nova assim, já atingiu os 18 anos de idade, e sempre pode ser aperfeiçoada, não faltando projetos para sua modernização. O destaque cabe para Projeto de Resolução do Senado 84, de 2007, que estabelece os limites para a dívida pública no âmbito federal, uma das grandes omissões da referida lei que precisa ser sanada, e rapidamente, pois a demora já tem causado prejuízos ao país. ${ }^{7}$ Não se pode conceber que estados e municípios tenham rígidos limites para o endividamento, mas a União, não.

E outros que se alinham ao que há de mais moderno em matéria orçamentária, como o PLS 428, de 2017, que institui o "plano de revisão periódica de gastos", que tem por objetivo "institucionalizar na administração pública federal um processo contínuo e transparente de revisão de gastos públicos”, como expõe o propositor, senador José Serra. Uma medida que está alinhada às mais recentes experiências internacionais, recomendada pela OCDE e pelo FMI e já adotada em diversos países. Esses planos, ou spending reviews, como referidos na literatura internacional especializada, têm sido reconhecidos como um importante instrumento de accountability, favorecendo o controle de gastos, a transparência e a responsabilidade fiscal. Permitem um melhor acompanhamento, pela sociedade e pelo Parlamento, da evolução e qualidade dos gastos públicos, facilitando os ajustes necessários e a manutenção do equilíbrio fiscal.

O novo presidente assumirá com amplo apoio popular, após vencer as eleiçôes em dois turnos, com a maioria dos votos. Não lhe faltará força política para promover as reformas que o Direito Financeiro requer.

O Direito Financeiro não pode esperar e precisa avançar. ${ }^{8}$

A sociedade brasileira aguarda essas medidas que, se até o momento não integraram os respectivos planos de governo, espera-se que venham a integrar antes da posse.

Ideias não faltam. Projetos, alguns iniciados, outros avançados e prontos para serem aprovados, também não. Aos candidatos, \#ficaadica!

6 Sem reforma, governo apresenta reforma alternativa. Veja, 19 de fevereiro de 2018. Disponível em: <https://veja.abril.com.br/economia/sem-reforma-governo-apresenta-pauta-alternativa>.

7 "É preciso notar que a demora em regulamentar o limite de endividamento da União trouxe prejuízos ao país ao incentivar a lassidão fiscal. A deterioração das contas públicas e as manobras criativas para ocultá-la, nos últimos anos são, infelizmente, boas amostras a este respeito", assevera o relator do projeto, senador José Serra.

8 O alerta já foi feito em 2016, em O Direito Financeiro precisa avançar, e a hora é agora, nesta edição, p. 263-268. 
